who, according to their shop stewards, did not take the test because as they put it "they didn't want to know." Some, not all, believed that cytotests simply told one that there was cancer of the womb, and "you find that out soon enough." The test of course is aimed at curable pre-cancer, but it seems that we had not pur this over in our invitations and posters in simple terms.

Dr. Scaife and his colleagues come to the same conclusion as the British Columbia workers in this field, that the key to success in any screening programme is the family doctor. If he says the test is of value, and even more if "nurse says so," then a busy housewife may well come for a test. Otherwise 70 to $80 \%$ of English women will ignore poster or postal invitations to take regular tests.

There are now fortunately in England large numbers of skilled cytologists. Their special skills are not at the the moment being fully exploited. Dr. Scaife's report is thus timely, and one hopes that many other doctors in family practice will set up a scheme to screen their patients. An ideal time is perkaps when their children come for their immunization against polio or diphtheria.

In cytology we have a method of protecting patients from a form of cancer which is at the moment killing 2,500 women in England each year. The total picture, allowing for cures, is 5,000 new cases each year. What this amounts to in suffering and misery for the patient and her family is only too well known. Two million cytotests are now done each year in England, always a start, but the target is 14 million a year and we now have cytologists to do this. Whether on Teesside with a $2 \%$ pick up rate or on the Pacific coast with $1 \%$ the key to the successful use of cytology is the family doctor who takes time to tell his patient that the test will protect from the risk of cancer. -I am, etc.,

Hugh Cameron McLaren Department of Obstetrics and Gynaecology. University of Birmingham

\section{Chronic Prostatitis}

SIR,-While it was a pleasure to see your leading article (1 July, p. 1) devoted to a subject which so far has been rather inadequately dealt with in the English language literature, there are a number of comments to be made on this contribution.

In the first place, it is not the experience of one of us who has made a fairly extensive study of prostatitis that gonococcal or non-specific urethritis are common precursors of this condition. This may be because cases of urethritis in the Services are usually promptly and effectively treated; it is therefore possible that the phenomenon of prostatitis following on venereal urethritis is an indication of late or inadequate antibiotic treatment of the primary condition.

While controversy does exist about the significance of pus cells in the prostatic fluid, most workers use the "high power field" or one-sixth inch objective and not the $1 / 12$ inch ( $2 \mathrm{~mm}$ ) objective as you have suggested; the figure of 10 pus cells per field taken as indicative of inflammation within the prostate is, in fact, 10 pus cell per high power or one-sixth inch field.

Following on the original work of Stamey and his associates, ${ }^{1}$ more recent studies on the secretion of antibiotics into the prostatic acini and ducts have shown that other drugs may reach potentially therapeutic levels in prostatic fluid. For example, trimethoprim has been found in prostatic fluid in concentrations higher than in simultaneous blood samples, ${ }^{2}$ and this has been confirmed both in experiments using the $\operatorname{dog}^{3}$ and also in humans. 4 Other studies ${ }^{5}$ have suggested that sulphonamides, clindamycin, and chloramphenicol may also reach inhibitory levels in prostatic secretion Although results of animal experiments ought to be regarded with caution, other work suggests that tetracycline, as opposed to the oxytetracycline recommended in your leader has more favourable pharmacological charac teristics in this context.-We are, etc.

Royal Naval Hospital Haslar,

\section{N. J. BLACKLOCK}

Gosport, Hants

Southmead Hospital,
Bristol

D. S. REEVES

1 Winningham, D. G., Nemoy, N. J., and Stamey, T. A., Nature, 1968, 219, 139.
Reeves, D. S., and Ghilchik, M., British fournal of Urology, 1970, 42, 66.

obb, C. A., Carroll, P. T., Tippett, L. O., and Langston, J. B., Invest

Fowle, A. S. E., and Bye, A., Proceedings of the 7th International Congress of Chemotherapy, Prague, 1971. In press.

5 Winningham, D. G., and Stamey, T. A., fournal of Urology, 1970, 104, 559. . G. Snell, M. E.
Reeves, D. S., Rowe, R. C. G., and Thomas, A. B. W. Proceedings of 2nd National Symposium on Urinary Tract Infection. London, 1972. In press.

Urology, M.' and Stamey, T. A., Fournal of

\section{Trapped Nerves}

SIR,-In a leading article (6 May, p. 307) you referred to my recent article on abdominal cutaneous nerve entrapment syndrome. ${ }^{1}$ As a matter of interest $I$ would like to relate some further information on the subject. Although I have made no attempt to map out changes in cutaneous sensation, I believe the effort would be fruitless. The cutaneous nerves in the area of the rectus muscle overlap and interconnect in a web of nerve fibres such that even when the cutaneous branch is severed at the rectus margin the loss of sensation is vague or imperceptible. Since the appearance of this article we have operated on four more patients. Severing the nerve at its exit from the rectus foramen has apparently given permanent relief to each patient, and confirms my impression that the symptom complex arises from the distal nerve rather than from a more proximal source.

Though I emphasized the fat hernia in the aetiology of the syndrome, I am increasingly impressed by the mechanism of traction against relatively unyielding softtissue structures. A further example of this mechanism is demonstrated in a patient I recently saw who gave a history of fractured rib at the costal margin. Apparently the seventh nerve was slightly displaced in its course. This resulted in traction on the nerve and typical symptoms of nerve entrapment. I strongly suspect that the patient with hypermobile ulnar nerve syndrome (the nerve subluxates from its groove at the elbow) suffers from a shortened nerve; perhaps the result of some asymmetry of the axial skeleton on the affected side. Since clavicle fractures are common, a deformity in this area may very well place the brachial plexus under tension, leading to a shortening of the ulnar nerve, which has to follow a somewhat longer course to the hand than do the medial and radial nerves. When the elbow is flexed, the ulnar nerve is dislocated from its groove or else it would be torn.

Though I have not documented it, I also feel that many chest pains are due to sensory nerve entrapment of the intercostal nerve with similar symptoms to that of abdominal nerve entrapment, and it does not take much imagination to suspect many other pain syndromes of being due to nerve entrapment in soft tissue. Ruegsegger ${ }^{2}$ has been injecting local anaesthetic into the muscles of the neck with excellent results in some headaches. Are these injections actually being placed in the exits of nerves from between and through the cervical muscles? Are the nerves being placed under undue traction by muscle spasm and/or minor skeletal misalignments?

Examining the diagrams of the acupuncturist, I am struck by the fact that many of the puncture points lie over muscular nerve exits. I believe we are only beginning to recognize the extent to which soft tissue nerve entrapment affects our daily lives, and I expect that more nerve entrapment syndromes will soon be elucidated in the literature.-I am, etc.,

W. V. APPLEgate Southern California Permanente Group, San Diego, California, U.S.A.

1 Applegate, W. V., Surgery, 1972, 71, 118 uegsegger, P., fournal of the American Medical

\section{Distress of Dying}

SIR,-May I endorse the plea of Dr. M. A. Simpson (22 July, p. 231) for more adequate teaching of care of the dying to medical students? When this is done, the cry for euthanasia-as voiced in the ensuing letter from Dr. S. L. Henderson Smith-will probably vaporize. As Dr. W. Dewi Rees pointed out in his survey ( $8 \mathrm{July,}$ p. 105), the conclusion to be drawn from his discovery that $74 \%$ of dying patients may suffer physical distress is that they need to be more adequately managed, not that they should be killed off.

For many terminal patients who cannot be satisfactorily cared for at home the ideal place is a specialized unit. Such centres are opening in England, and one hopes that before long every community will have its hospice. Many patients who would otherwise have died in hospital may be managed at home if the general practitioner and hospice staff join forces. 1

Encouraging though this development may be, it cannot proceed unless there is proper teaching of care of the dying to students.-I am, etc.,

London E.8

RICHARD LAMERTON

1 McNulty, B., Nursing Times, 1970, 66, 1160.

\section{Alpha-fetoprotein and Gastric Carcinoma}

SIR,-The association between alphafetoprotein and hepatocellular carcinoma is well known. We wish to report an example of the rarer association with gastric carcinoma. ${ }^{1-3}$

A 63-year-old man was admitted with a 